Physical Disabilities: Education and Related Services, 2015, 34(1), 1-13. doi: 10.14434/pders.v34i1.13258

(C) Division for Physical, Health and Multiple Disabilities

PDERS

ISSN: 2372-451X

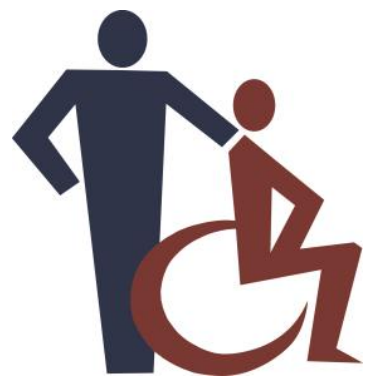

http://scholarworks.iu.edu/journals/index.php/pders/index

Promising Practice

\title{
ACCOMMODATING STUDENTS WITH EPILEPSY OR SEIZURE DISORDERS: EFFECTIVE STRATEGIES FOR TEACHERS
}

Juliet E. Hart Barnett

Arizona State University

Catherine Gay

Arizona State University

\begin{abstract}
The most common chronic neurological condition in children is epilepsy. Because it often occurs in childhood, epilepsy is likely the most common neurological condition encountered by school professionals including teachers. Given the impact that epilepsy can have on academic functioning and specifically on the day-to-day performance of a student in the classroom, it is important for teachers to be aware not only of the presence of the disorder but also of the potential consequences and appropriate ways to handle these consequences should they arise. Herein we synthesize recommendations from several scientific sources to provide specific, evidence-based strategies that teachers of students with epilepsy can employ in the classroom as part of their naturally occurring instructional routines. These practical tips have useful application for both general and special education teachers.
\end{abstract}

Keywords: physical impairment; epilepsy; teacher preparation 


\section{Introduction}

Mrs. Johnson was in the middle of a reading lesson in her inclusive $3^{\text {rd }}$ grade class when one of her students shouted out, "I think there might be something wrong with Bobby!" Sure enough, when Mrs. Johnson approached Bobby he was staring blankly ahead, blinking rapidly, and smacking his lips together. Attempts to draw Bobby out of his seizure were unsuccessful.

Mr. Smith was monitoring his $6^{\text {th }}$ period general education algebra class as they took a math test. All of a sudden, from the back of the room he heard a loud bang. When he looked back, he saw Susie lying on the ground; her arms and legs were stiffening and jerking. The other students in the class were clearly confused and shocked by the situation and had no clue how to react.

These scenarios are examples of two possible ways that epilepsy or a seizure disorder may manifest itself in a classroom setting. Would you know how to handle such situations?

The most common chronic neurological condition in children is epilepsy. Epilepsy is a condition characterized by recurrent and unprovoked seizures, which are temporary neurological abnormalities that result from unregulated electrical discharges in the brain (Shorvon, Guerrini, \& Andermann, 2011). Seizures occur when abnormal neuron firing within the brain causes a sudden change in cerebral function. According to the Centers for Disease Control and Prevention (CDC; www.cdc.gov) about 2.3 million people in the United States (about 1 in 100) have epilepsy. One in 26 individuals will develop this condition at some point in his/her lifetime. The CDC further reports that children under the age of two are especially vulnerable to the condition. Among children, the prevalence of seizures is around four to eight in every 1,000 children. Epilepsy onset most commonly occurs either before the age of two or around the onset of puberty (Black \& Hynd, 1995) with $30 \%$ of cases occurring by the age of five and $75 \%$ occurring by the age of 20 (Barrett \& Sachs, 2006). Because it often occurs in childhood, epilepsy is likely the most common neurological condition encountered by school professionals including teachers (Barrett \& Sachs, 2006).

It is important to note that seizures and epilepsy are not synonymous. An epileptic seizure is a temporary occurrence of signs and/or symptoms due to abnormal excessive or synchronous neuronal activity in the brain. Epilepsy is a disorder characterized by a long-term predisposition to generate epileptic seizures and by the neurobiological, cognitive, psychological, and social manifestations of this condition. That is, a seizure is a singular event and epilepsy is the condition involving recurring, unprovoked seizures (Epilepsy Foundation, 2014).

Seizures are classified as either partial or generalized (Spiegel, Cutler, \& Yetter, 1996). A partial seizure typically begins at a specific site in the brain and impacts only one side of the brain. Partial seizures may result in impaired consciousness (complex) or not (simple). Unlike partial seizures, generalized seizures affect both hemispheres of the brain. Generalized seizures can be classified as tonic-clonic or absence seizures. Tonic-clonic seizures are associated with repetitive stiffening (tonic) and jerking (clonic) of the extremities while absence seizures involve a lapse in consciousness without significant motor movements (Fisch \& Olejniczak, 2006). Absence seizures are often described as brief staring episodes and may occur several times throughout the day (Benbadis \& Berkovic, 2006). Other generalized seizure types may also occur, including 
myoclonic seizures, which consist of sporadic jerks, usually on both sides of the body, and atonic seizures, which consist of a sudden and general loss of muscle tone, particularly in the arms and legs, often resulting in a collapse (Spiegel et al., 1996). Generalized seizures can result in a period of confusion and semi-consciousness known as the post-ictal period (Barrett \& Sachs, 2006). During this period, children may especially struggle with tasks involving attention, learning, and memory (Wodrich, Kaplan, \& Deering, 2006). A graphic depicting seizure types and subtypes is provided in Figure 1.
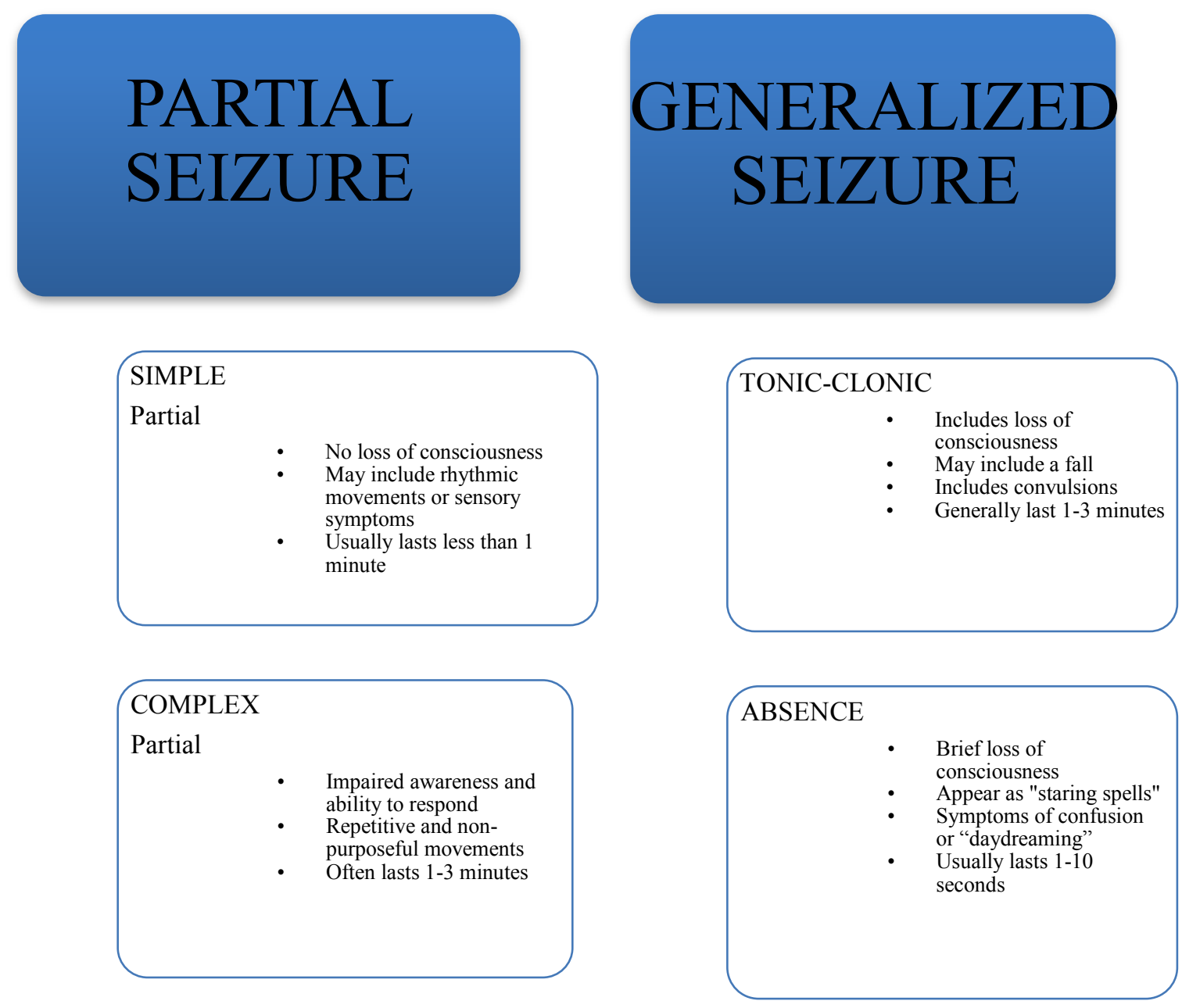

Figure 1. Graphic representation of seizure types and subtypes.

Three particular characteristics of epilepsy that may disrupt a child's learning process include the seizure activity itself, cognitive deficits associated with the area of the brain affected by the seizures, and side effects of anti-epileptic drugs (Wodrich et al., 2006). Impairments associated with actual seizure activity can lead to missed instruction, general slowed cognitive functioning, limited awareness, and memory problems for events occurring around the time of the seizure, which may include instruction if seizures occur at school. Impairments caused by a seizure may differ depending upon which part of the brain is impacted by the seizure. For example, seizures impacting the hippocampus (which plays an important role in the formation of memories) are 
more likely to cause problems with memory while seizures in the frontal lobe (which is associated with executive functioning) are more likely to cause problems with planning, organizing, and problem solving (Wodrich et al., 2006).

In addition to the medical impact of epilepsy, students with epilepsy are likely to experience a variety of social and academic difficulties (Bishop \& Boag, 2006). Social consequences associated with epilepsy include fear of negative perception if others are aware of the diagnosis, difficulty making new friends (Baker et al., 2008), emotional problems, mental health problems, and low self-esteem (Miller, Palermo, \& Grewe, 2003). Academic achievement can also be significantly impacted by many aspects of epilepsy including seizure activity, coexisting cognitive deficits, side effects of anti-epileptic drugs (Wodrich \& Cunningham, 2008), absenteeism, peer acceptance, and teacher understanding and expectations (Reilly \& Ballantine, 2011). Academic difficulties are frequently observed in the areas of mathematics, spelling, reading comprehension, and word recognition (Black \& Hynd, 1995), with some children with epilepsy experiencing difficulties across all academic areas (Reilly \& Ballantine, 2011). Additionally, parents report lower academic expectations and students with epilepsy are more likely to qualify for special education services than are other low achieving students (Barrett \& Sachs, 2006).

The most common treatment for epilepsy is the use of anti-epileptic drugs (AEDs). The goal of these medications is to prevent seizures with minimal side effects from the medications. However, most AEDs are associated with numerous side effects including lethargy, aggression, irritability, and hyperactivity, as well as decreases in intellectual functioning, attention, and memory. Side effects are most especially evident when more than one AED is necessary to control seizure activity, which occurs in approximately 10 to 15 percent of patients (Barrett \& Sachs, 2006).

Given the impact that epilepsy can have on academic functioning and specifically the day-to-day performance of a student in the classroom, it is important for teachers to be aware not only of the presence of the disorder but also of the potential consequences and appropriate ways to handle these consequences should they arise. However, recent research (Wodrich et al., 2011) has demonstrated that teachers lack adequate knowledge about epilepsy and confidence working with a student with epilepsy. Further, teachers specifically noted that they would like to obtain additional information about the medical, social, and academic accommodations that are effective for students with epilepsy (Wodrich et al., 2011). Therefore, in this article we synthesize recommendations from several sources to provide specific, evidence-based strategies that teachers of students with epilepsy can employ in the classroom as part of their naturally occurring instructional routines. These practical tips have useful application for general and special education teachers.

\section{Manage the Medical Impact of Epilepsy}

First, it is important for the school team to develop an individualized seizure action plan. This team should include parents, teachers, school nurse, physician, and any other individuals who can inform the team regarding the health needs of the student (Nabors, Little, Akin-Little, \& Iobst, 2008). The development of a seizure action plan assists school personnel in the 
implementation of efficient medical treatment, which may decrease the need for visits to the emergency room. The ultimate goals of a seizure action plan include providing treatment, minimizing class disruptions, and allowing the student to return to class as soon as possible. The seizure action plan should include parent and physician contact information, important medical history, specific seizure information (e.g., type, duration, frequency, triggers), specific first aid precautions to take in the event of a seizure, emergency protocols (including when to call 911), and treatment protocols. The team should individualize the seizure plan to outline what constitutes a medical emergency for the student and to include appropriate responses to seizure activity (O’Dell, O’Hara, Kiel, \& McCullough, 2007). Sample seizure action plans are available on the Epilepsy Foundation website (www.epilepsyfoundation.org).

Teachers can be valuable assets in monitoring any potential side effects from or changes in a student's seizure activity. These may include any noticeable changes in the student's behavior, emotions, physical demeanor, intellectual abilities, or seizure activity (Barrett \& Sachs, 2006). During a seizure, it is important to take note of any loss of consciousness, confusion, unresponsiveness, breathing problems, or vision and hearing problems (O'Dell et al., 2007). Following the seizure activity, teachers should document the length or duration of the seizure (from the initial onset), any confusion, sleepiness, headaches, or speech problems (epilepsyfoundation.com). School staff should record all observation information and communicate the information with the parents. This documentation may be recorded through the use of a seizure logbook that can be sent home each day or on individual seizure activity observation record forms.

\section{Provide Social Supports}

Students with epilepsy often experience negative social consequences due to their condition. These consequences may include social isolation, low self-esteem, and trouble making or keeping friends (Baker et al., 2008; Miller et al., 2003). Teachers can do several things to help minimize or prevent the occurrence of these potentially damaging social outcomes. First, it is important that teachers not over-protect the child. While it may seem like limiting the student's physical activity is in his or her best interest, doing so may actually encourage social isolation and interfere with many opportunities to learn and practice important social skills. Therefore, with the permission of the student's physician and based on guidelines outlined in the seizure action plan, the student should be allowed to participate in appropriate school activities. Teachers should use caution in situations that may trigger seizure activity such as excessively hot weather conditions.

Second, the time immediately following the occurrence of a seizure is a particularly important opportunity to prevent social and emotional challenges. Other students in the class may be startled after witnessing their classmate experiencing a seizure and will likely have questions and concerns. Without proper information, the students may be fearful and may even shun the student with epilepsy. With consent from the parents of the student with epilepsy as well as assent from the student, classmates should be given factual, age-appropriate information in order to allay their fears and promote understanding and empathy (epilepsyfoundation.com). In a spirit of self-determination (Hart \& Brehm, 2013), it is also useful to talk with the student who had the seizure about this discussion and invite the student's leadership and participation in educating his 
or her classmates. In particular, older students who have experienced years of the disorder may have come to doubt their ability to achieve autonomy and control in their lives. As such, an opportunity to share information with classmates about the disorder may serve as an empowering experience. If the student with epilepsy does not wish to participate, he or she should later be informed about what was discussed.

During the classroom discussion, it is important to define the seizure in developmentally appropriate terms in relationship to the students' age or grade level. Teachers should explain that what happened was called a "seizure," it occurred because the student's brain was temporarily sending mixed signals to the rest of the body, and the student's brain is now working properly again. In addition, it should be explained that the seizure occurred because the student has a condition called epilepsy, and that epilepsy is not a disease and is not contagious. For additional resources, as well as more specific information on ways to address these topics with students of different ages, teachers can visit www.epilepsyclassroom.com. This website provides lesson plans for ages prekindergarten through $12^{\text {th }}$ grade, which are designed to educate students about epilepsy and promote understanding and acceptance of individuals affected by the disorder. In addition to providing these lessons following a seizure, it may be very helpful to provide this information to students prior to the occurrence of a seizure in the classroom. This will help students understand what is happening in the event of a seizure and will help prepare them for the most appropriate responses.

Third, it is likely that the student with epilepsy may frequently miss school due to seizures and needed medical follow-up appointments. The student will consequently miss opportunities to learn and engage in social interactions with peers. Teachers can incorporate cooperative learning activities and other forms of group work as part of instructional activities in order to maximize social opportunities and reduce the toll that excessive absences may have taken on the social relationships of students with epilepsy. It is crucial that teachers continually and creatively seek ways to integrate the student with epilepsy into the social fabric of the classroom. In addition, Table 1 contains several web-based resources for teachers specific to meeting the needs of students with epilepsy.

\section{Provide Needed Academic Accommodations}

Students with epilepsy may demonstrate academic challenges in reading, writing, and mathematics. These difficulties may be due to memory and attention deficits, AED side effects, general slowed cognitive functioning, or absenteeism (Wodrich et al., 2006). There are many classroom accommodations that teachers can put into place to reduce the impact of these factors for students.

To minimize the impact of deficits in memory and attention, teachers can ensure that instructions are simple, do not include extraneous information, and are provided at an appropriate pace. It may also be beneficial to provide instructions in multiple formats (e.g., auditory and visual). This will ensure that the directions are repeated or cued if there are concerns regarding short-term memory deficits. A specific curricular accommodation that may help students with epilepsy contend with their memory and organizational deficits is the use of graphic organizers. Graphic organizers come in several forms including webs, maps, or concept diagrams, and assist learners 
Table 1

Online Epilepsy Resources for Teachers

\begin{tabular}{|c|c|}
\hline Website & Description \\
\hline www.epilepsyfoundation.org & $\begin{array}{l}\text { Hosted by the Epilepsy Foundation, this website } \\
\text { provides factual information about epilepsy, } \\
\text { resources for teachers including recommendations } \\
\text { about medical, social, and academic } \\
\text { accommodations for use in the classroom. }\end{array}$ \\
\hline www.epilepsy.com & $\begin{array}{l}\text { This site provides factual information about } \\
\text { epilepsy and its impact on an individual's life. } \\
\text { This site also outlines many of the concerns that } \\
\text { may arise at school. }\end{array}$ \\
\hline Www.epilepsyclassroom.com & $\begin{array}{l}\text { This website can be used to improve the } \\
\text { understanding of epilepsy for parents, teachers, } \\
\text { and students. This site contains pre-made lesson } \\
\text { plans for grades prekindergarten through } 12^{\text {th }} \text { that } \\
\text { can be used to help explain epilepsy to children of } \\
\text { all ages. }\end{array}$ \\
\hline http://nichcy.org/disability/specific/epilepsy & $\begin{array}{l}\text { The National Dissemination Center for Children } \\
\text { with Disabilities provides detailed and useful } \\
\text { information on characteristics, treatment options, } \\
\text { fact sheets, and strategies for teachers working } \\
\text { with students with epilepsy. }\end{array}$ \\
\hline
\end{tabular}

with recall and comprehension of material (Bulgren, Marquis, Lenz, Schumaker, \& Deshler, 2009). Graphic organizers provide a visual representation in the form of a framework and can be hand drawn or computer generated (Turnbull, Turnbull, Wehmeyer, \& Shogren, 2013). For instance, a web organizer could be constructed to display major story elements such as characters, plot, setting, and themes in a novel. The student can then fill in key information as it is being read or use the organizer as a post-reading comprehension builder.

Assessment accommodations are also important to consider. Because many students with epilepsy have difficulty with declarative memory (i.e., memory for specific facts; Wodrich et al., 2006), administering tests that assess recognition rather than recall (i.e., multiple choice rather than fill-in-the-blank) or tests that assess broad understanding instead of knowledge or specific facts may provide a more accurate representation of overall understanding. Other appropriate testing accommodations may include breaking longer tests into small parts to be administered over several sessions to avoid fatigue as well as to reduce the cognitive load required in any single sitting. Moreover, flexible timing and setting may include allowing the student to take the test on a different day or at a different time. For example, requiring a student to take a test Tuesday afternoon following a seizure Tuesday morning would not be appropriate. Additionally, if the student's AED causes drowsiness or fatigue in the mornings it may be more appropriate for him or her to take tests in the afternoon. 


\section{Collaborate with Families}

Some students' epilepsy may result in minimal adverse educational impact; therefore, these students' needs are effectively addressed through accommodations within a 504 plan. Other students, however, experience an adverse impact on educational performance as a result of their epilepsy, requiring individualized instruction through an Individualized Education Plan (IEP). Notwithstanding, full parental participation is underscored both in the 504 plan process and the IEP as mandated by the requirements of the Individuals with Disabilities Education Act (IDEA, 2006; More, Hart, \& Cheatham, 2013), and this includes parents of students with epilepsy. Specifically, students with disabilities and their parents are partners with educators in decisionmaking about students' educational programming and should experience full opportunities for participation and support in the delivery of special education services. Furthermore, teachers should implement collaborative conferences with families, communicate effectively with families, and evaluate collaborative activities (Turnbull et al., 2013). Forging such supportive, mutually respectful relationships between families and school professionals represents the cornerstone of collaborative partnerships (Blue-Banning, Summers, Nelson, Frankland, \& Beegle, 2004) and makes a positive difference in the quality of the student's educational experience (Newman, 2003). Family-centered school professionals that promote the formation of collaborative partnerships with parents may empower parents to serve as a beneficial resource (Dunst, Trivette, \& Hamby, 2007).

Much of the responsibility for educating others about epilepsy falls on the shoulders of the parent and at times even the student with the disorder. A collaborative team approach where parental input is valued is essential. Parents should be encouraged to provide background information to the student's teacher rather than assuming that the teacher has sufficient knowledge of epilepsy. Although any educator may work with a student with epilepsy at some point in his or her career, it is unreasonable to expect that every teacher will have awareness of the disorder or have knowledge of best practices to use with this population of students.

Although most students with seizure disorders will have plans in place, it is the responsibility of each teacher and other service providers to be well familiar with each plan. Additionally, teachers can make the most of parents' expertise and role as a resource by seeking out and listening to their guidance on what works best for their children (Turnbull et al., 2013). This parental input matched with research-based instructional strategies can be a powerful approach. Yet, despite the power of instructional strategies, ongoing two-way communication must be at the core of all techniques employed. Ensuring that parents have the opportunity to emphasize their child's strengths and make all school personnel aware of these assets should happen as early in the school year as possible, preferably even before the school year begins. In some cases, parents withhold medical diagnoses from school personnel due to fear of stigma (Spiegel et al., 1996). The disclosure of such information can be encouraged through the use of a cheerful and welcoming "start of the school year letter" sent home in which teachers invite caregivers to report on their child's strengths and preferences; any disorder the child contends with; and any medical, social, or academic problems that accompany this disorder (refer to Table 2 for a sample letter). Such a letter may allay parental fears related to disclosing epilepsy information about their child. In addition, a daily communication notebook going between home and school can be a valuable tool to maintain collaborative partnerships throughout the school year. 
Table 2

Sample Start of School Year Letter to Parents

\section{PARENT SURVEY}

Welcome to our classroom! Please take some time to provide the following information to help me get to know your child.

Child's name:

Birthday: Age

Parent/guardian name(s):

Parent/guardian phone number(s):

Best time to contact:

Medical Information

Please list any medical concerns:

Do these medical concerns cause any difficulties in the classroom? Yes No If yes, please list these difficulties:

Is your child on any medications? Yes No

If yes, will your child need to take medication while at school? Yes No

How/when would you like to be contacted in the event of a medical emergency? 
Let us now revisit the situation experienced by Mrs. Johnson and Bobby. In this case, Mrs. Johnson has discussed Bobby's seizure history with his parents as well as other school staff. She is aware that Bobby occasionally has absence seizures in which he appears distracted and has minor facial tics. She knows that these seizures typically last between two and three minutes, occur about once a month, and that Bobby needs about an hour to lie down in a dark place to recover. This information is all documented in Bobby's seizure action plan and has been distributed to other school staff that he interacts with. Mrs. Johnson has also discussed the situation with the students in the class. Thanks to this preparation, the students in the class were able to notify Mrs. Johnson as soon as they noticed a problem. Mrs. Johnson was then able to note the seizure characteristics and document that this seizure was of an average length and typical presentation. In addition, Bobby was able to take a break in the nurse's office before returning to the classroom. Finally, Mrs. Johnson called Bobby's parents to notify them that a seizure occurred and that she was sending home a copy of the seizure incident report for them to share with his physician if needed.

\section{Conclusion}

Because epilepsy is the most common neurological condition in children and affects about four to eight in every 1,000 children (CDC; www.cdc.gov), it is likely that teachers will instruct a student with epilepsy at some point during their teaching career (Barrett \& Sachs, 2006). In this article we provided several recommendations for classroom accommodations that can be easily implemented to alleviate the potential medical, social, and academic challenges that may arise among students diagnosed with epilepsy. Moreover, we highlighted the importance of building and maintaining a collaborative partnership between families and schools. This partnership is especially important for students with chronic medical conditions such as epilepsy because parents can provide valuable information regarding the student's strengths, weaknesses, medical and educational history, as well as recommendations for accommodations that have been successful in the past. Implementing the suggested strategies in a spirit of collaboration with families can help ensure that students with epilepsy experience educational success. 


\section{References}

Baker, G. A., Hargis, E., Hsih, M. M., Mounfield, H., Arzimanoglou, A., Glauser, T., \& Lund, S. (2008). Perceived impact of epilepsy in teenagers and young adults: An international survey. Epilepsy \& Behavior, 12, 395-401. http://dx.doi.org/10.1016/j.yebeh.2007.11.001

Barrett, R. P., \& Sachs, H. T. (2006). Epilepsy and seizures. In L. Phelps (Ed.), Chronic healthrelated disorders in children: Collaborative medical and psychoeducational interventions (91-110). Washington, DC, US: American Psychological Association.

Benbadis, S. R., \& Berkovic, S. F. (2006). Absence seizures. In E. Wyllie (Ed.), The treatment of epilepsy: Principles and practice (4th ed., pp. 305-315). Philadelphia: Lippincott, Williams \& Wilkins.

Bishop, M., \& Boag, E. M. (2006). Teachers' knowledge about epilepsy and attitudes toward students with epilepsy: Results of a national survey. Epilepsy \& Behavior, 8, 397-405. http://dx.doi.org/10.1016/j.yebeh.2005.11.008

Black, K. C., \& Hynd, G. W. (1995). Epilepsy in the school aged child: Cognitive-behavioral characteristics and effects on academic performance. School Psychology Quarterly, 10, 345-358. http://dx.doi.org/10.1037/h0088314

Blue-Banning, M., Summers, J. A., Nelson, L. L., Frankland, C., \& Beegle, G. P. (2004). Dimensions of family and professional partnerships: Constructive guidelines for collaboration. Exceptional Children, 70(2), 167-184. http://dx.doi.org/10.1177/001440290407000203

Bulgren, J. A., Marquis, J. G., Lenz, B. K., Schumaker, J. B., \& Deshler, D. D. (2009). Effectiveness of question exploration to enhance students' written expression of content knowledge and comprehension. Reading and Writing Quarterly, 25(4), 271-289. http://dx.doi.org/10.1080/10573560903120813

Dunst, C. J., Trivette, C. M., \& Hamby, D. W. (2007). Meta-analysis of family-centered helpgiving practices research. Mental Retardation and Developmental Disabilities Research Reviews, 13, 370-378. http://dx.doi.org/10.1002/mrdd.20176

Epilepsy Foundation (2014). A revised definition of epilepsy. Retrieved March 18, 2015 from: http://www.epilepsy.com/article/2014/4/revised-definition-epilepsy

Fisch, B. J., \& Olejniczak, P. W. (2006). Generalized tonic-clonic seizures. In E. Wyllie (Ed.), The treatment of epilepsy: Principles and practice (4th ed., pp. 281-304). Philadelphia: Lippincott, Williams \& Wilkins.

Hart, J. E., \& Brehm, J. (2013). Promoting self-determination among students with disabilities: A model for training elementary students to self-advocate for IEP accommodations. Teaching Exceptional Children, 45, 40-48. 
Individuals With Disabilities Education Act, 20 U.S.C. § 4301 et seq. (2006). http://dx.doi.org/10.1016/j.yebeh.2009.11.013

Miller, V., Palermo, T. M., \& Grewe, S. D. (2003). Quality of life in pediatric epilepsy: Demographic and disease-related predictors and comparison with healthy controls. Epilepsy \& Behavior, 4, 36-42. http://dx.doi.org/10.1016/S1525$\underline{5050(02) 00601-7}$

More, C., Hart, J. E., \& Cheatham, G. A. (2013). Language interpretation for diverse families: Considerations for special education teachers. Intervention in School and Clinic 49, 113120. http://dx.doi.org/10.1177/1053451212472229

Nabors, L. A., Little, S. G., Akin-Little, A., \& Iobst, E. A. (2008). Teacher knowledge of and confidence in meeting the needs of children with chronic medical conditions: Pediatric psychology's contribution to education. Psychology in the Schools, 45, 217-226. http://dx.doi.org/10.1002/pits.20292

Newman, T. (2003). Children of disabled parents: New thinking about families affected by disability and illness. Lyme Regis: Russell House Publishing.

O’Dell, C., O’Hara, K., Kiel, S., \& McCullough, K. (2007). Emergency management of seizures in the school setting. The Journal of School Nursing, 23, 158-165. http://dx.doi.org/10.1177/10598405070230030601

Reilly, C., \& Ballantine, R. (2011). Epilepsy in school-aged children: More than just seizures? Support for Learning, 26, 144-151. http://dx.doi.org/10.1111/j.1467-9604.2011.01501.x

Shorvon, S. D., Guerrini, R., Andermann, D. (2011). Introduction to the concept of provoked epilepsy. In S. D. Shorvon, F. Andermann, \& R. Guerrini. (Eds). The causes of epilepsy. Common and uncommon causes in adults and children. Cambridge University Press, Cambridge, pp. 625-630. http://dx.doi.org/10.1017/CBO9780511921001.090

Spiegel, G. L., Cutler, S. K., \& Yetter, C. E. (1996). What every teacher should know about epilepsy. Intervention in School and Clinic, 32, 34-38. http://dx.doi.org/10.1177/105345129603200107

Turnbull, A. P., Turnbull, H. R., Wehmeyer, M. L., \& Shogren, K. (2013). Exceptional lives: Special education in today's schools (7th ed.). Upper Saddle River, NJ: Merrill/Prentice Hall.

Wodrich, D. L., \& Cunningham, M. M. (2008). School-based tertiary and targeted interventions for students with chronic medical conditions: Examples from Type 1 Diabetes Mellitus and Epilepsy. Psychology in the Schools, 45, 52-62. http://dx.doi.org/10.1002/pits.20278 
Wodrich, D. L., Jarrar, R., Buchhalter, J., Levy, R., \& Gay, C. (2011). Knowledge about epilepsy and confidence in instructing students with epilepsy: Teachers' responses to a new scale. Epilepsy \& Behavior, 20, 360-365.

Wodrich, D. L., Kaplan, A. M., \& Deering, W. M. (2006). Children with epilepsy in school: Special service usage and assessment practices. Psychology in the Schools, 43, 169-181. http://dx.doi.org/10.1002/pits.20123 